\title{
Role of functional echocardiographic parameters in the diagnosis of bronchopulmonary dysplasia-associated pulmonary hypertension
}

\author{
Soham Dasgupta $\mathbb{1}^{1} \cdot$ Joan C. Richardson ${ }^{2} \cdot$ Ashraf M. Aly $^{3} \cdot$ Sunil K. Jain ${ }^{2}$ \\ Received: 6 June 2020 / Revised: 22 December 2020 / Accepted: 11 February 2021 / Published online: 8 March 2021 \\ (c) The Author(s), under exclusive licence to Springer Nature America, Inc. 2021
}

\begin{abstract}
Echocardiogram (echo) is a commonly used noninvasive modality for the diagnosis of bronchopulmonary dysplasia associated pulmonary hypertension (BPD-PH). Though not considered the gold standard for the diagnosis of BPD-PH, it is an extremely valuable tool in the neonatal and pediatric population, especially when cardiac catheterization is not feasible. In addition to the traditional echo parameters that are used to assess the presence of BPD-PH, much attention has been recently placed on newer bedside echo measures, the so-called functional echo parameters, to aid and assist in the diagnosis. This review article provides a brief introduction to BPD-PH, describes the pitfalls of traditional echo parameters and details the newer echo modalities currently available for the diagnosis of neonatal $\mathrm{PH}$.
\end{abstract}

\section{Introduction}

Survival of the extremely preterm infants has increased with advances in neonatal/perinatal therapies. The reported incidence of extreme prematurity in the US was $1.38 \%$ out of a total of 52,302 births in 2018 [1]. Despite the widespread use of antenatal steroids for lung development, surfactant and gentle ventilatory strategies, bronchopulmonary dysplasia (BPD) remains the most common complication of prematurity affecting up to two-thirds of infants born at $\leq 29$ weeks gestational age. "Classic BPD" was characterized by pulmonary fibrosis secondary to oxygen toxicity and volumetric/ barometric trauma by mechanical ventilation $[2,3]$.

In the current era, "New BPD" is seen in extremely premature infants born at 24-28 weeks' gestation.

No support was received for this work in the form of grants and/or equipment and drugs

Soham Dasgupta

dasguptasoham@gmail.com

1 Division of Pediatric Cardiology, Boston Children's Hospital, Harvard University, Boston, Massachusetts, USA

2 Division of Neonatology, University of Texas Medical Branch, Galveston, TX, USA

3 Division of Pediatric Cardiology, University of Texas Medical Branch, Galveston, TX, USA
Compared to "Classic BPD", "New BPD" is characterized by disordered pulmonary development $[4,5]$. BPD associated PH (BPD-PH), defined as an increased pulmonary arterial pressure, complicates the postnatal course of premature infants. In extremely premature infants, BPD$\mathrm{PH}$ is associated with poor outcomes with high morbidity and mortality [6]. The American Heart Association (AHA) and American Thoracic Society (ATS) recommend screening for BPD-PH in premature infants [7]. However, due to lack of consensus regarding the screening and diagnostic criteria of BPD-PH, the true incidence of BPD$\mathrm{PH}$ is unknown. Awareness of the prevalence, risk factors, and time-sensitive mortality of BPD-PH will allow physicians to develop screening guidelines and preventive strategies.

This review focuses on the use of newer bedside echocardiographic (echo) measures, for the screening and diagnosis of BPD-PH in premature infants and highlights the practical limitations of using routine echo and cardiac catheterization as the gold standard.

\section{Definition of pulmonary hypertension}

The guidelines by the ATS/AHA on pediatric PH defined $\mathrm{PH}$ as a mean pulmonary artery pressure (mPAP) $\geq 25$ $\mathrm{mmHg}$ at sea level with a pulmonary capillary wedge pressure $<15 \mathrm{~mm} \mathrm{Hg}$ and an indexed pulmonary vascular resistance (PVR) of $>2$ iWU in infants $>3$ months of age 
[7]. The task force of the European Society of Cardiology and the European Respiratory Society defined PH as mPAP $\geq 25 \mathrm{mmHg}$ at rest or $\geq 30 \mathrm{mmHg}$ during exercise by cardiac catheterization or estimated systolic PAP (sPAP) $\geq 40$ $\mathrm{mmHg}$ by ECHO [8]. This definition is mainly used in older pediatric and adult patients as it does not consider the physiological drop in mPAP in the first 3 months of age. Most recently, the 6th World Symposium on Pulmonary Hypertension recommended amending the definition of $\mathrm{PH}$ to a $\mathrm{mPAP} \geq 20 \mathrm{mmHg}$ and to include $\mathrm{PVR} \geq 3 \mathrm{iWU}$ to identify pre-capillary $\mathrm{PH}[9]$.

\section{Setting for screening of BPD-PH in preterm infants}

In premature infants with BPD, increased PVR leads to increased PAP which may cause right ventricular hypertrophy and subsequent RV failure. Known risk factors for BPD-PH include extreme prematurity, intrauterine growth restriction (IUGR), oligohydramnios, maternal preeclampsia, length of mechanical ventilation, and prolonged oxygen supplementation [6]. Even though there is high morbidity and mortality associated with BPD-PH, there is a lack of consensus on the definition and screening of BPD-PH in premature infants.

In 2015, the AHA/ATS provided guidelines for patients with BPD-PH [7]. Recently, the Pediatric Pulmonary Hypertension Network (PPHN) recommended 34 practical clinical recommendations for the evaluation, diagnosis, and management of BPD-PH. Screening for BPD-PH by echo should be considered for premature infants requiring ventilator support at $\geq 7$ days, and premature infants with moderate-severe BPD at 36 weeks post-menstrual age (PMA). The recommendations stated that premature infants with mild BPD may be monitored clinically, however, if infants with mild BPD deteriorate or fail to improve, then echo should be used to screen for BPD-PH. Standardized echo parameters to be used with these evaluations were also provided [10].

Following the AHA/ATS guidelines for screening premature infants with BPD, a survey was performed which included experienced neonatologists. The majority of the neonatologists recognized an increasing incidence of BPD$\mathrm{PH}$ but formal screening protocols varied significantly. Only $46 \%$ of respondents had Neonatal Intensive Care Unit protocols aligned with the AHA/ATS recommendations to screen for BPD-PH in infants with moderatesevere BPD [11]. One of the major limitations is that there is no evidence-based risk calculator to monitor BPD-PH currently and the development of such a tool may assist in the identification and screening of appropriate cases of BPD-PH.

\section{Timing of BPD-PH screening}

In premature infants, lung injury leads to BPD-PH emphasizing the importance of early interventions prior to development of irreversible changes, which was also endorsed by the National Institute of Health [12] and has been demonstrated in animal models [13]. Even though the AHA/ATS recommend screening for BPD-PH in premature infants with BPD at 36 weeks PMA [7], recent studies have suggested benefits of early screening of premature infants for BPD-PH. Mourani et al. found $42 \%$ infants had early PH (diagnosed on day 7) and $14 \%$ late $\mathrm{PH}$ (at 36 weeks PMA) with early PH being a risk factor for late $\mathrm{PH}$ [5]. Infants with late $\mathrm{PH}$ had greater duration of oxygen therapy and increased mortality. Among infants diagnosed with BPD-PH after 2 months of age, only 2/3rd infants survived at 6 months and only half of infants survived 2 years after the diagnosis. These results suggest that even subtle early echo features of pulmonary vascular disease in the first week are risk factors for BPD-PH. A case series of premature infants with BPD-PH treated with sildenafil demonstrated no significant improvement in respiratory scores and echo findings when therapy was started after 36 weeks PMA [14]. In summary, the natural history of BPD-PH is unclear based on the current literature. Premature infants with BPD are at increased risk of developing BPD-PH and early screening for BPD-PH by echo may be helpful to find premature infants at risk of BPD-PH.

\section{Assessment of BPD-PH}

\section{Echocardiogram}

\section{Introduction}

An echo probe has piezoelectric crystals. An electric potential applied to such a crystal results in mechanical distortion causing the crystal to resonate producing ultrasonic waves. An ultrasound beam traveling through the body will have some of its energy reflected back to the transducer and some of its energy transmitted forward [15]. Two dimensional (2D) imaging allows structures to be viewed in real time in a cross-section of the heart [16]. The most common 2D views are the parasternal long axis, the parasternal short axis, and the apical four chamber view. The M-mode echo, which provides a one dimensional view, is used for fine measurements [16].

In echo, the velocity of moving structures is assessed by the Doppler principle [15]. Estimates of blood-flow velocity can be made by comparing the frequency change between the transmitted and reflected sound waves. The simplified Bernoulli equation is used to measure a pressure differential 
across an orifice: $\Delta P=4\left(V_{2}^{2}-V_{1}^{2}\right)$ where $V_{1}=$ the velocity proximal to the obstruction and $V_{2}=$ the velocity distal to the obstruction [15].

The two most common types of doppler used in echo are the continuous wave (CW) and the pulse wave (PW) doppler [16]:

Continuous wave $(\mathrm{CW})$ doppler: It measures velocity along the entire length of the ultrasound beam and not at a specific depth. It has range ambiguity but there is no theoretical limit to the maximal velocity that can be measured.

Pulse wave (PW) doppler: It is used to measure localized velocity values of turbulent flow.

In the neonatal population, echo is the most commonly used modality for the evaluation of BPD-PH to estimate PAP and $\mathrm{RV}$ function as it is noninvasive, portable, and can be performed at the bedside [17]. Echo is useful to estimate the severity and diagnosis of BPD-PH, guiding initiation of therapy with pulmonary vasodilators, monitoring the response to treatment provided and finally monitoring BPD-PH while weaning treatment. Echo should be considered in all patients who meet the criteria of moderate-severe BPD according to the NIH definition and should be performed as early in the course as possible to enable early initiation of therapy [18].

Traditionally, increased tricuspid regurgitant (TR) jet velocity, right to left shunt across the foramen ovale and flattening of the interventricular septum (IVS) were used to predict elevated RV pressures and in turn SPAP in the absence of right ventricular outflow tract obstruction [14] (Figs. 1, 2 and 3). TR jet velocity is the most commonly used echo parameter to measure $\mathrm{RV}$ systolic pressure (RVSP) by CW doppler. A TR jet velocity $>2.5 \mathrm{~m} / \mathrm{s}$ is suspicious for $\mathrm{PH}$ and further workup may be considered especially in a preterm infant at risk for BPD-PH [19].
However, the TR jet needs a reproducible holosystolic envelope and is subject to technical difficulties in obtaining the appropriate images. In addition, the TR jet doppler velocity envelope may be affected by the presence of pulmonary stenosis or a significant ventricular septal defect. Mourani et al. found that a reliable TR jet doppler envelope is found in only $61 \%$ of pediatric echoes [20].

The presence of a right to left or bidirectional shunt at the level of the foramen ovale is a surrogate marker of increased $\mathrm{RV}$ pressures [21]. Interventricular septal curvature is an alternative marker of RV pressure based on the alignment of IVS (Table 1). Normally, the IVS bows into the right ventricle during systole due to the left ventricular systolic pressure being higher than the RVSP. A rounded contour of the IVS is suggestive of infra-systemic pulmonary pressures whereas a flattened IVS during systole is seen with suprasystemic pulmonary pressures. A flattened IVS that bows into the left ventricle during systole is highly suggestive of elevated pulmonary artery pressures although such interpretation is subject to inter-observer variability [22].

Echo evaluation is limited by lack of standardized definitions, difficulty in estimating the pulmonary pressures when a TR jet is absent and the technical skill of the operator. Other limitations include poor correlation between echo findings and cardiac catheterization in both adults and infants with PH [23, 24]. Fisher et al. compared echo findings performed during cardiac catheterization in 25 children under the age of two years and showed that echo was able to diagnose $\mathrm{PH}$ in $79 \%$ and to determine the severity in only $47 \%$ of cases [24].

The definitive diagnosis of $\mathrm{PH}$ is usually made by measuring the mPAP during cardiac catheterization, which

\section{Fig. 1 Figure showing tricuspid regurgitant jet velocity in a patient with severe pulmonary hypertension. The measured tricuspid regurgitant jet velocity is $5 \mathrm{~m} / \mathrm{s}(+$ sign $)$ which translates to an estimated right ventricular systolic pressure of $100 \mathrm{mmHg}$ + right atrial pressure.}

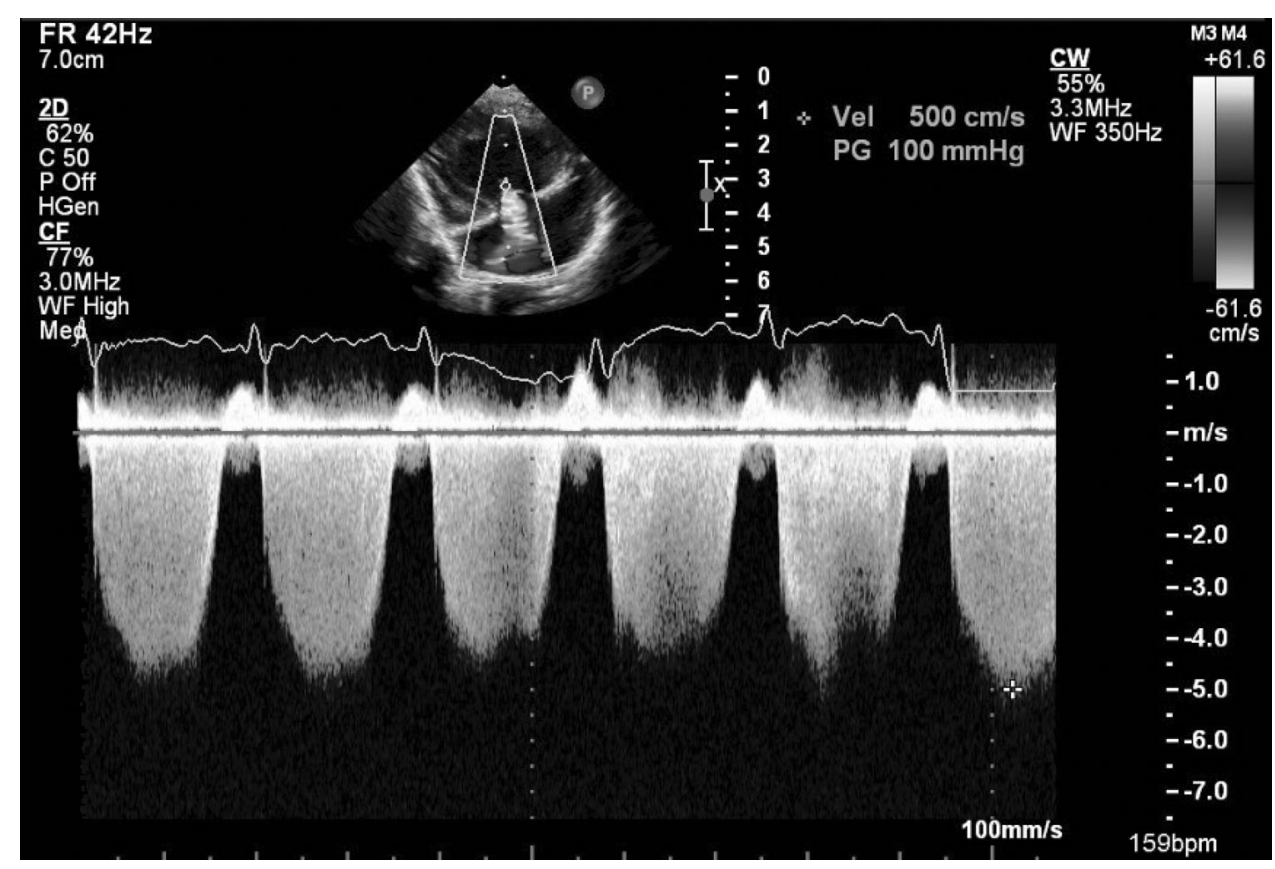


Fig. 2 Subcostal coronal view in a patient with severe pulmonary hypertension. There is right to left shunting across a patent foramen ovale (blue flow, arrow).

Fig. 3 Parasternal short axis view in a patient with severe pulmonary hypertension.

There is severe systolic interventricular septal flattening (arrow).
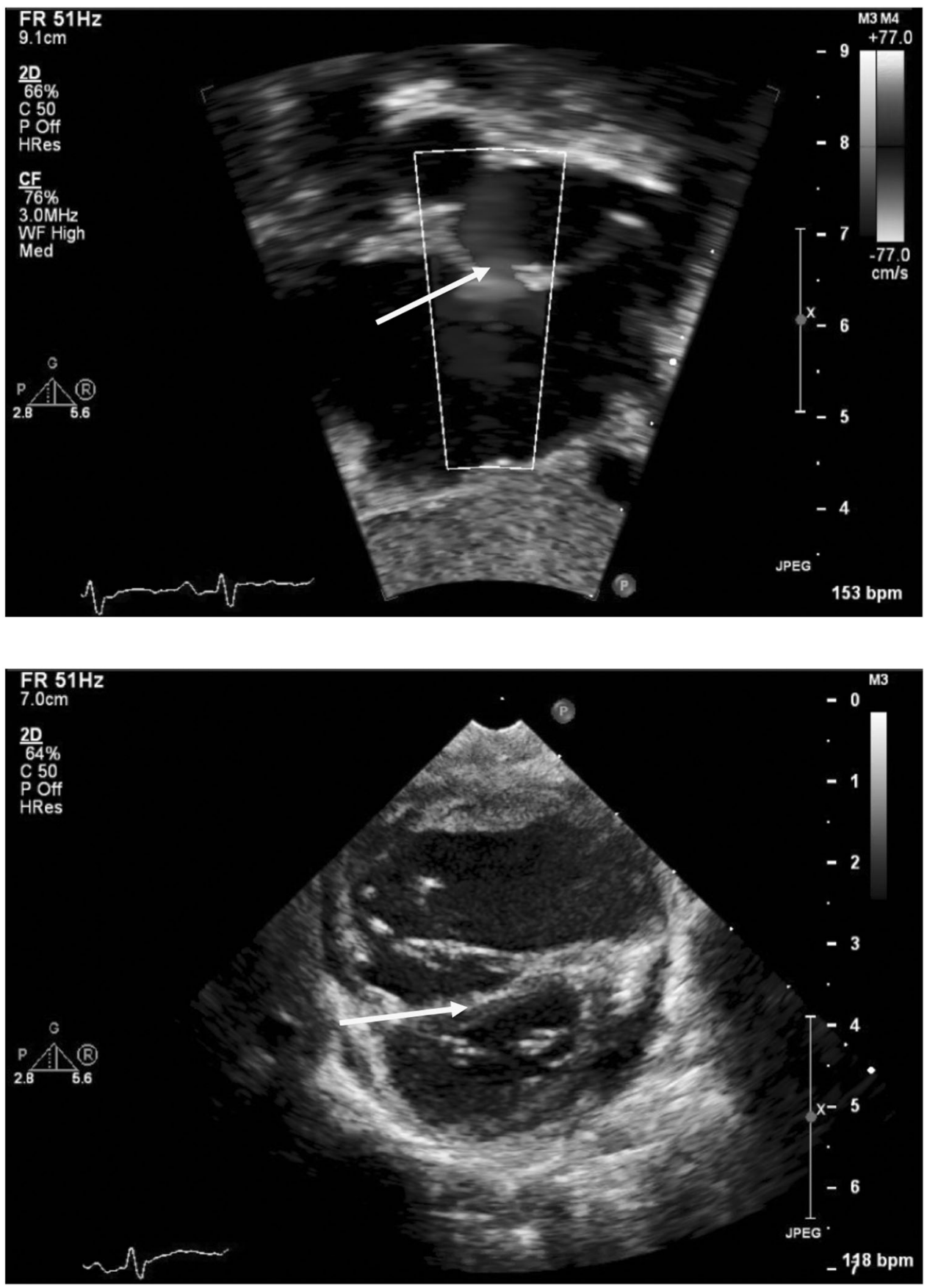

Table 1 Estimation of right ventricular systolic pressure based on left ventricular configuration.

\begin{tabular}{ll}
\hline Left ventricular configuration & Estimated right ventricular pressure \\
\hline O-shaped $\mathrm{LV}^{*}$ & $<50 \%$ of $\mathrm{LVP}^{\#}$ \\
D-shaped $\mathrm{LV}^{*}$ & $50-100 \%$ of $\mathrm{LVP}^{\#}$ \\
Crescent-shaped LV & $\geq 100 \%$ of $\mathrm{LVP}^{\#}$ (supra systemic \\
& pressure)
\end{tabular}

$L V$ left ventricle.

$L V P$ left ventricular pressure allows for vasoreactivity testing to determine responsiveness to oxygen and other pulmonary vasodilators such as inhaled nitric oxide. However, invasive procedures, anesthesia, and exposure to ionizing radiation must be carefully considered in sick infants and cardiac catheterization is not always practical [17]. Hence, other noninvasive methods of identifying $\mathrm{PH}$ in this population have been proposed. As an alternative to routine echo with measurement of TR jet, IVS alignment and inter-atrial shunting, functional echo parameters can also be used for the estimation of PAP. 
Fig. 4 Parasternal short axis view showing a continuous wave doppler tracing of a pulmonary regurgitant jet. This shows a minimum enddiastolic velocity of $2.67 \mathrm{~m} / \mathrm{s}$ (arrow) consistent with an estimated diastolic pulmonary artery pressure of $28 \mathrm{mmHg}$.

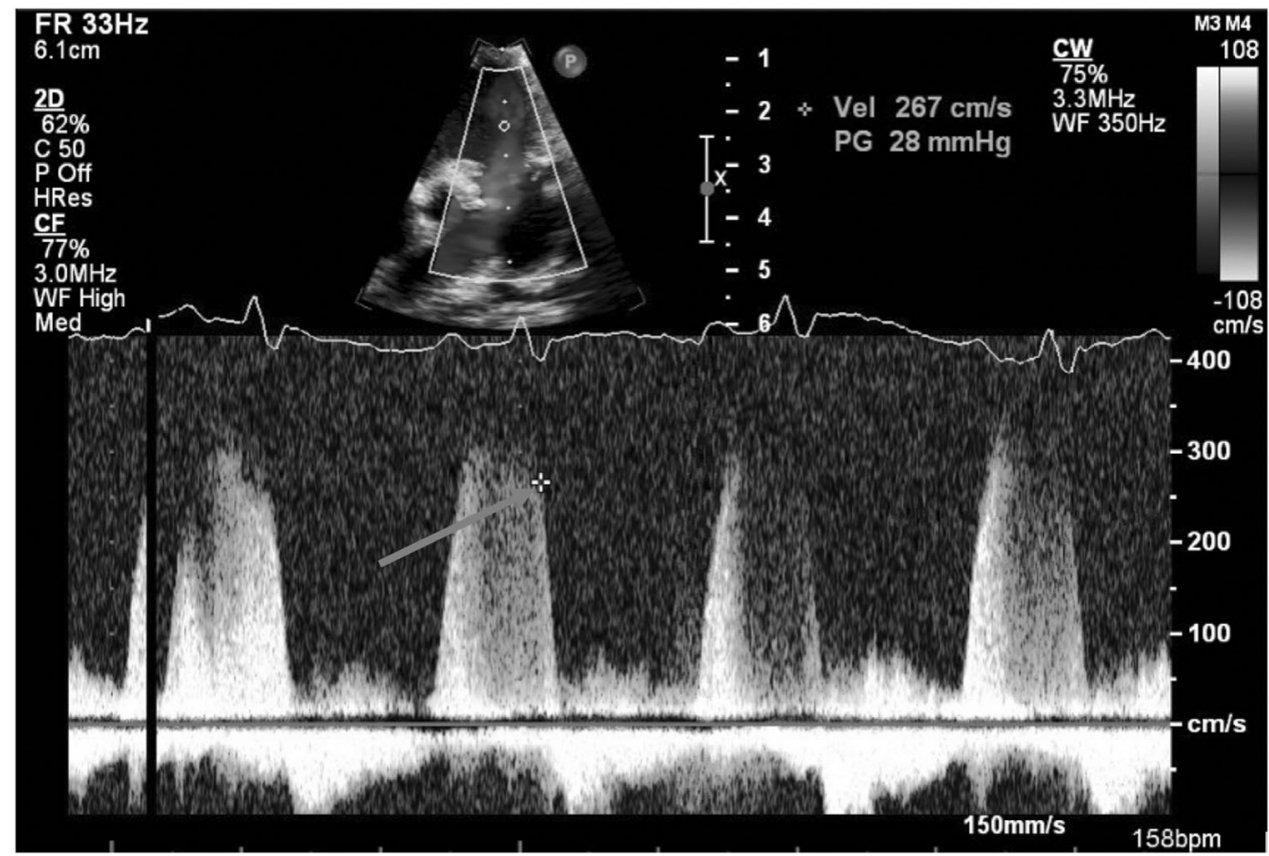

\section{Functional echo}

In this manuscript, we define functional echo parameters as the newer echo modalities that are available for the screening and diagnosis of $\mathrm{PH}$, which strays from the traditional parameters of TR jet velocity, IVS alignment, and inter-atrial shunting. In the context of BPD-PH, RV function assessment is crucial. The principal manifestations of RV dysfunction in infants with BPD-PH are a triad of changes in RV configuration (dilation and hypertrophy of RV), right to left interaction (IVS shifting) and RV systolic dysfunction. However, assessment of RV function is extremely challenging by echo, and IVS alignment is subject to inter-observer variability. In infants at high risk of BPD-PH, serial functional echoes can be used for risk stratification, diagnosis, estimation of severity, and monitoring the response to treatment of BPD-PH.

\section{Hemodynamic assessment of RV}

\section{Estimation of pulmonary artery pressure (PAP)}

\section{Systolic PAP}

The estimation of the SPAP is traditionally based on the peak velocity of the TR jet. The simplified Bernoulli equation using $\mathrm{CW}$ doppler to assess the TR jet describes the relationship of TR and RVSP as a surrogate of sPAP in the absence of RV outflow tract obstruction [25]. RVSP may be underestimated by TR jet assessment in cases with moderate to severe TR and also because of a suboptimal doppler spectral envelope. In addition, overestimation of RVSP may occur if there is pulmonary valve stenosis. So although a complete TR jet envelope may provide an accurate estimation of sPAP, care should be taken to ensure that there is no RV outflow tract obstruction and the doppler envelope does not represent another lesion such as a ventricular septal defect.

\section{Mean PAP and diastolic PAP}

A pulmonary regurgitation (PR) signal is obtained in the parasternal short-axis view. Mean PAP and diastolic PAP (dPAP) can be estimated from the early-diastolic and enddiastolic PR velocity respectively, using the simplified Bernoulli equation [26] (Fig. 4). A limitation of mPAP and dPAP estimations is that the PR signal may be poor [23]. An overestimation of the right atrial pressure and the use of inadequate doppler signals are also identified as frequent pitfalls [24].

\section{Left ventricular systolic eccentricity index (LV-sEI)}

Another objective way of estimating PAP is by calculating the LV-sEI. LV-sEI is the ratio of LV dimensions parallel and perpendicular to the IVS. LV-sEI is measured in the short axis parasternal view (Fig. 5). It is defined as the ratio of D2:D1 where $\mathrm{D}_{1}$ is the LV short-axis diameter perpendicular to the septum and $D_{2}$ is the left ventricle short-axis diameter parallel to the septum. Normal LV-sEI ratio is 1 and it increases in BPD-PH with a value $>1$ suspicious for BPD-PH in a preterm infant [19]. LV-sEI allows 
Fig. 5 Parasternal short axis view in a patient with severe pulmonary hypertension. Measurement of left ventricular systolic eccentricity index (D2/D1) is performed (D2: red line; D1: yellow line).

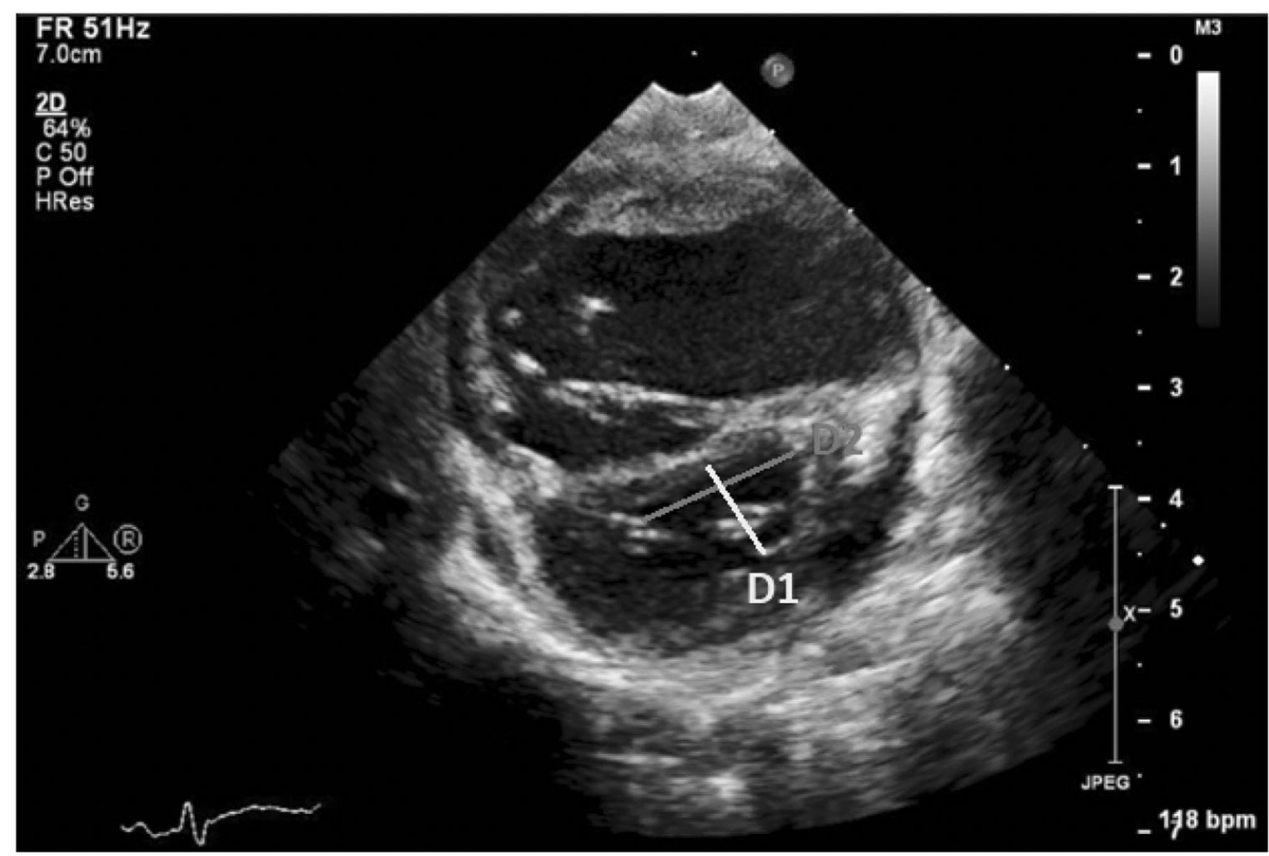

quantification of subjective IVS flattening. Revanna et al. found that LV-sEI was significantly higher in infants with BPD-PH [27]. A recent study of a prospectively enrolled cohort at high risk for BPD showed that the sEI was the only objective parameter among the evaluated assessments of RV mechanics that was independently associated with BPD severity at 36 weeks PMA [28]. The sEI is highly reproducible and is independent of the angle of insonation. The sEI reflects interventricular interactions, with changes in sEI driven by perturbations of RV/LV pressures [28].

\section{Pulmonary artery acceleration time (PAAT)}

Pulmonary artery acceleration time (PAAT) is the interval (in $\mathrm{ms}$ ) from the onset of ejection to the peak flow velocity and may be used for the assessment of PVR (Fig. 6). PAAT is a validated noninvasive, feasible, and reproducible echo modality to measure PVR in BPD-PH [29]. Healthy controls without $\mathrm{PH}$ have PAAT $>120 \mathrm{~ms}$ [30]. PAAT $<90 \mathrm{~ms}$ reliably detects high PAP whereas a value $<40 \mathrm{~ms}$ suggests severe PAP. A PAAT $<70 \mathrm{~ms}$ in a preterm infant is highly suggestive of elevated PVR and potential BPD-PH [19]. In adults at risk for $\mathrm{PH}$, a PAAT $<100 \mathrm{~ms}$ indicates a high probability of increased PAP [31]. The normal PW doppler profile in the right ventricular outflow tract is smooth, parabolic, and without "notching" of the doppler envelope with a notch suggestive of elevated PVR [32].

\section{Right ventricular ejection time (RVET) and PAAT:RVET}

RVET is the time interval between the onset and cessation of systolic flow with PAAT:RVET being inversely related to
PAP during cardiac catheterization [33]. PAAT:RVET ratio has high sensitivity and specificity in detecting the triad of elevated PVR, decreased pulmonary arterial compliance, and RV dysfunction [29]. In the pediatric population, patients without PH usually have PAAT:RVET $\geq 0.31$ while a PAAT $<90 \mathrm{~ms}$ and PAAT:RVET $<0.31$ reliably detect elevated PVR with a sensitivity and specificity $>90 \%$ [29]. Since absolute PAAT values are heart rate dependent; the PAAT: RVET is proposed to correct for the shortening of ejection at higher heart rates [34]. Kosturakis et al. found that even though PAAT and RVET shorten with increasing heart rate, the ratio of PAAT:RVET remains unchanged [33].

\section{Global and regional functional assessment of the RV}

\section{RV longitudinal systolic function (Tricuspid annular plane systolic excursion-TAPSE)}

The tricuspid annular plane systolic excursion (TAPSE) reflects longitudinal excursion of the tricuspid annulus toward the apex and is measured by M-mode from the 4chamber view [35, 36] (Fig. 7). It measures the distance of systolic excursion of the tricuspid annulus which has a good correlation with RV global systolic function. Although TAPSE is reproducible and simple to measure, accurate measurement depends on the angle of the echo probe and preload [37]. Reference values of TAPSE measurements in adults, pediatric, term, and premature infants range are available [38-40] with reduced TAPSE values having a high specificity for RV dysfunction [41]. With sustained PH 
Fig. 6 Parasternal short axis view showing a pulse wave doppler tracing across the pulmonary valve. There is a short pulmonary artery acceleration time (PAAT) of $63.3 \mathrm{~ms}$ (asterisk) consistent with severe pulmonary hypertension.

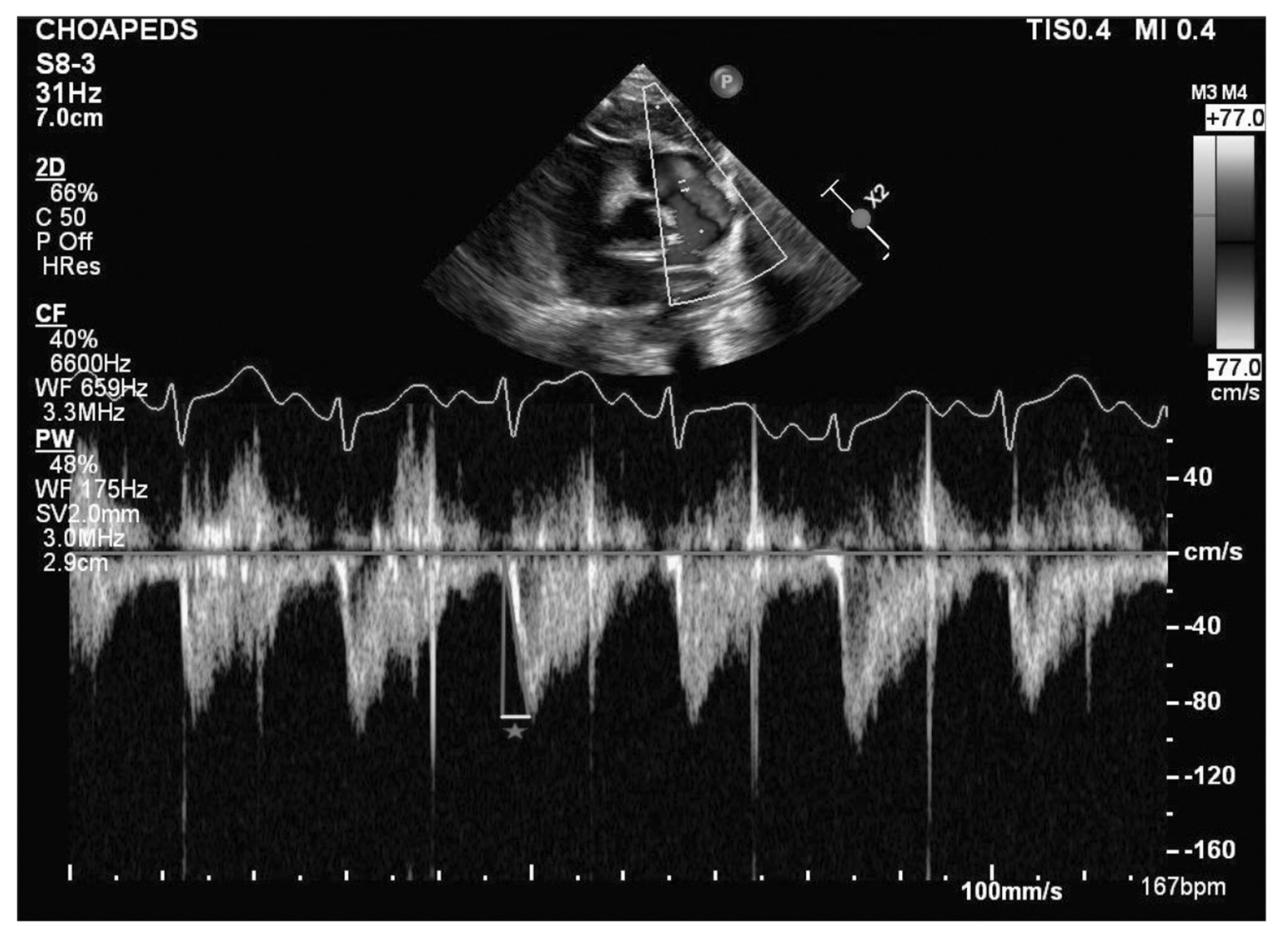

Fig. 7 Measurement of tricuspid annular plane systolic excursion (TAPSE) by aligning an M-mode cursor parallel with the right ventricular free wall as it meets the tricuspid annulus from the apical four-chamber view. The distance between the enddiastolic (vertical arrow) and end-systolic (horizontal line) represents TAPSE.

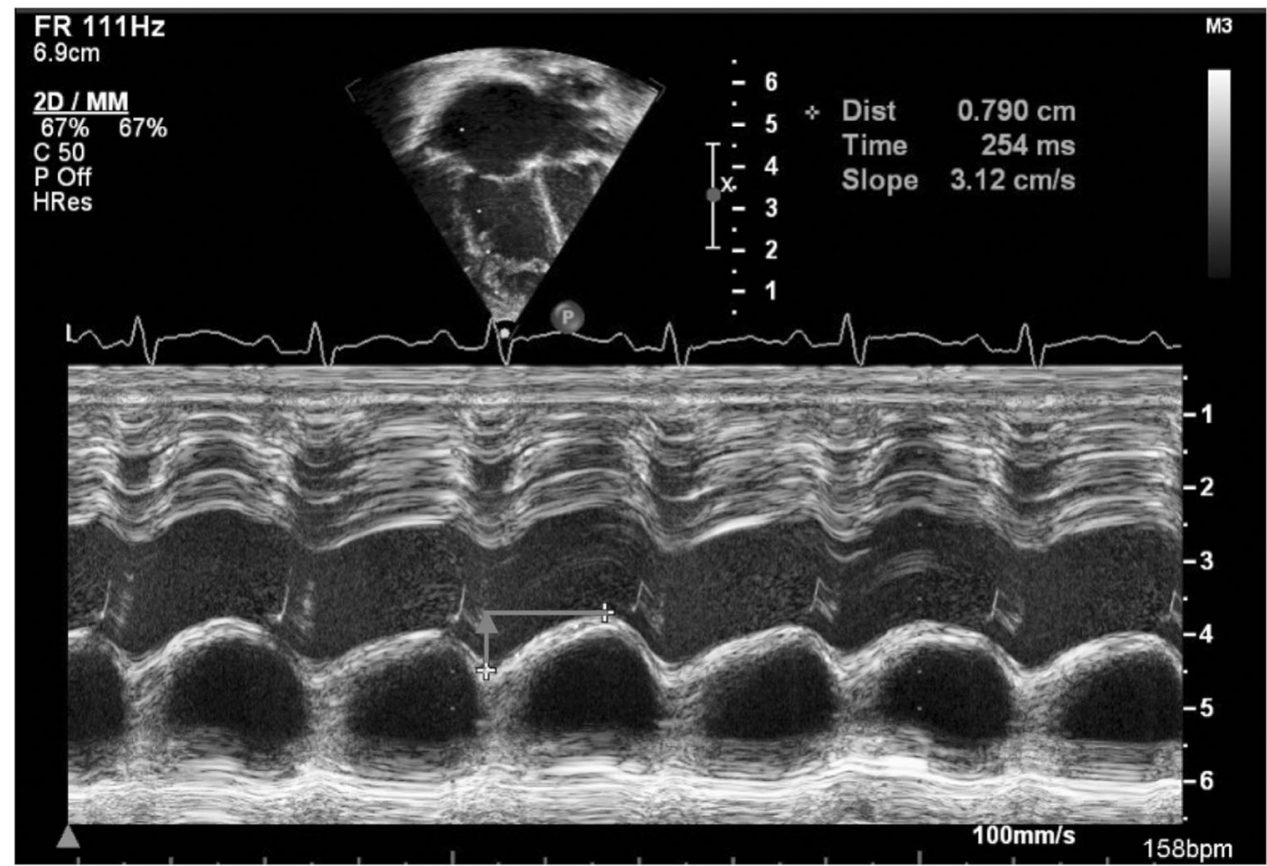

over years in children and young adults, TAPSE values decrease [42]. In a prospective study of children with $\mathrm{PH}$, treatment-induced changes in TAPSE were associated with improved survival [43]. A TAPSE $\mathrm{z}$ score $<-3$ in a preterm infant is highly suspicious for BPD-PH [19]. TAPSE significantly improves after initiation of $\mathrm{PH}$ therapy in pediatric patients and may be used to monitor the response to $\mathrm{PH}$ therapy [44]. However, it must be remembered that TAPSE does not take into account segmental RV dysfunction.

\section{RV fractional area change}

The RV fractional area change (FAC), representing the ratio of systolic area to diastolic area, is a commonly used index of RV contractility. RV FAC is less reproducible than TAPSE but accounts for apical, basal, radial, and longitudinal function [41]. In a recent pediatric $\mathrm{PH}$ study, RV FAC correlated with indexed RV stroke work and TAPSE [45]. Studies in the neonatal literature have suggested that a 


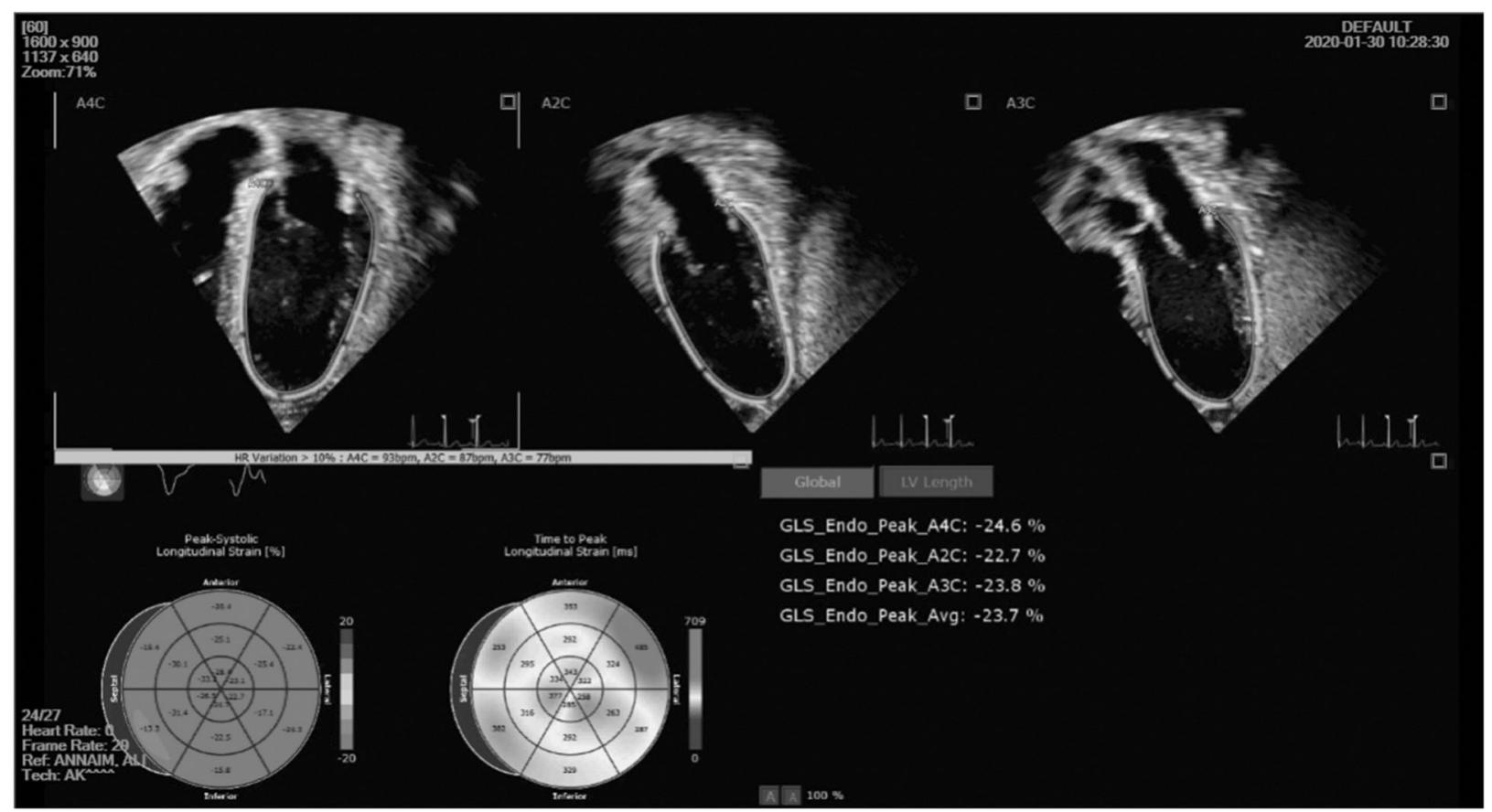

Fig. 8 Global Longitudinal Strain is measured from the apical four-chamber, three-chamber and two-chamber view. This figure is an example of a patient with normal global longitudinal strain.

number less than $30 \%$ is abnormal and suggests diminished RV function [46]. Combining RV FAC with other parameters for the assessment of RV function may allow a more comprehensive assessment of children with $\mathrm{PH}$. A limitation of this method is that the RV FAC is dependent on preload.

\section{Deformation imaging (RV strain and strain rate)}

Deformation imaging is used to assess global and regional myocardial function (Fig. 8). It allows for direct assessment of myocardial muscle fiber shortening and lengthening throughout the cardiac cycle via strain and strain rate [47]. RV global longitudinal peak systolic strain and strain rate were significantly affected in adults with $\mathrm{PH}$, and studies have shown that strain and strain rate correlate with invasive and noninvasive markers of PH [48, 49]. In a small pediatric PH study, strain was found to be an earlier predictor of RV dysfunction [50]. A recent study in neonates with BPD-PH has suggested that an RV peak longitudinal strain greater than -14 is a discriminative marker of BPD-PH [51]. The limitations of strain and strain rate measurements are the relatively low temporal solution of 2D speckle tracking in the presence of high heart rates and the long post-processing times [25].

\section{Tissue doppler}

Tissue doppler velocities may be used to assess regional myocardial function [25] (Fig. 9). Tissue doppler velocities are dependent on geometry, which has implications in children with congenital heart disease, who have variable RV size, mass, and geometry [52]. In adults, tissue doppler indices measurements have been shown to have a specificity of $100 \%$ to identify patients with precapillary $\mathrm{PH}$ [53]. Pediatric $\mathrm{PH}$ patients had lower systolic $\left(S^{\prime}\right)$ and early-diastolic $\left(E^{\prime}\right)$ velocities at the lateral tricuspid, septal, and lateral mitral walls [54]. In addition, RV tissue doppler indices have been found to correlate well with invasive pulmonary hemodynamics in pediatric patients with $\mathrm{PH}$ [55]. Currently, there are no validated tissue doppler values for the diagnosis of BPD-PH in neonates. The limitations of tissue doppler indices are predominantly related to dependence on preload, dependency on heart size, and the angle of interrogation.

\section{Myocardial performance index (Tei index)}

The Tei index evaluates global ventricular function by measuring the ratio of isovolumic contraction and relaxation time intervals to ventricular ejection [56] (Fig. 10). This is obtained via tissue doppler on the RV free wall and a PW doppler near the tricuspid annulus [23]. Isovolumetric contraction time, isovolumetric relaxation time, and ejection time of the RV are then measured. The longer the isovolumetric phases, the higher the Tei index and the worse the RV performance. The RV Tei index correlates well with right heart catheterization parameters $[57,58]$. In a recent study, neonates with BPD-PH had a higher mean MPI as compared to those without $\mathrm{PH}(0.46 \pm 0.16$ vs $0.34 \pm 0.21)$ 
Fig. 9 Apical four-chamber view of the heart with tissue doppler deployed on the lateral tricuspid valve annulus. This is an example of a patient with normal tricuspid annular tissue doppler measurements.
Fig. 10 Measurement of the myocardial performance (Tei) index. Sampling at tips of the mitral valve leaflets, in the apical four-chamber view, enables the measurement of the time interval between the end and the start of transmitral flow:

Isovolumetric contraction time $($ ICT) + Ejection time $($ ET $)+$ Isovolumetric Relaxation time (IRT). Sampling in the left ventricular outflow tract, just below the aortic valve allows the measurement of the ET. The myocardial performance index is then be expressed by the formula $(\mathrm{ICT}+\mathrm{IRT}) / \mathrm{ET}$.
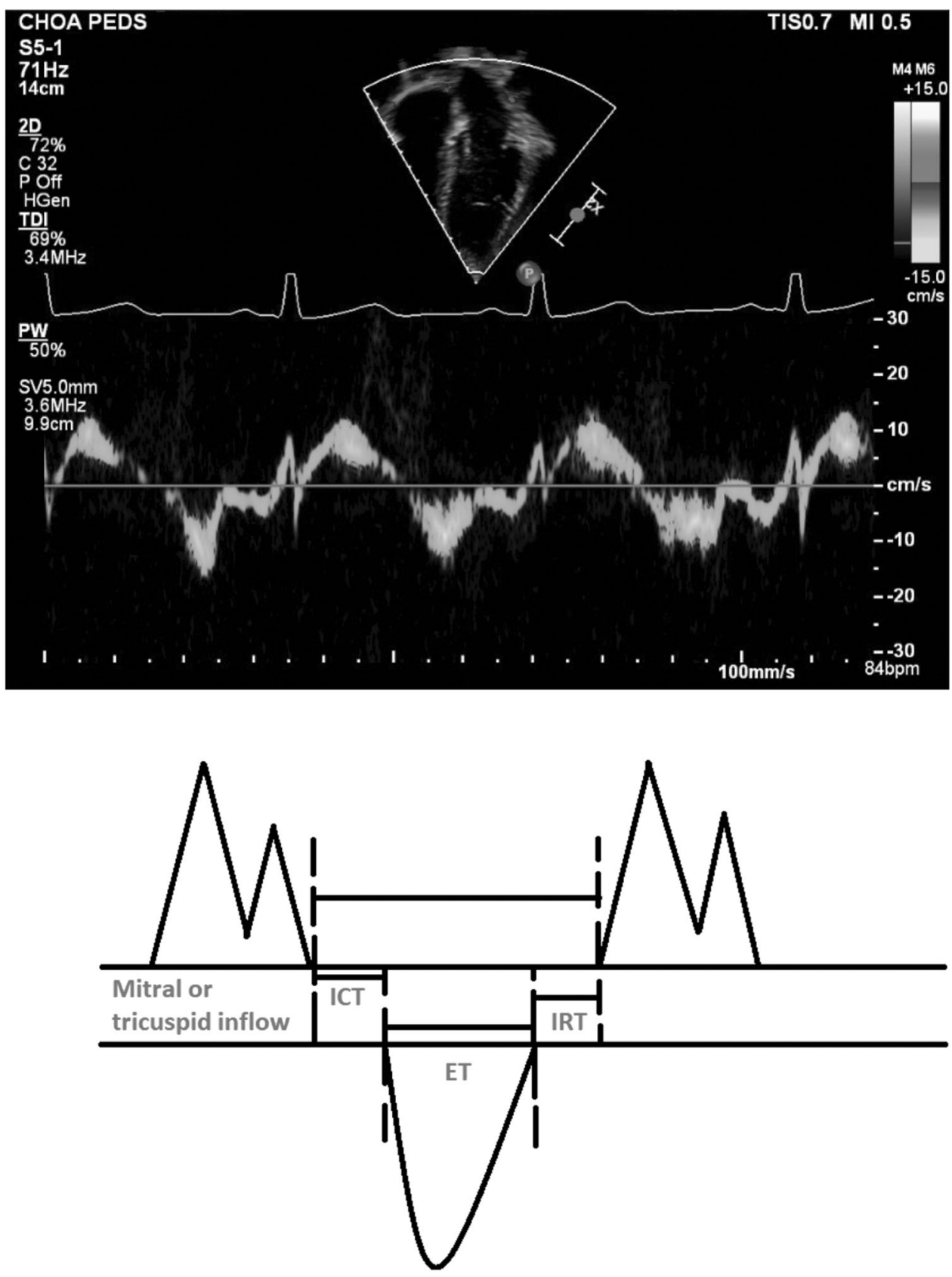

LV or RV outflow although absolute cut-off values are lacking in this population [59]. Advantages of the Tei index are that it is a combined ventricular-vascular index and can be measured independent of ventricular geometry. Its limitations include the inability to allow distinction between systolic and diastolic dysfunction.

\section{D echo}

3D echo provides significant advantages for measurement of RV size, mass, and ejection fraction [60] (Figure. 11). Studies have demonstrated consistency in RV mass and volume measurements by 3D echo and cardiac MRI [61]. Kong et al. reported that regional and global RV systolic dysfunction in adult $\mathrm{PH}$ patients measured by $3 \mathrm{D}$ echo was inversely related to the PAP and PVR [62]. In adults with PH, good correlation was found in the calculation of RV ejection fraction and RV end-diastolic-volume determined by either $3 \mathrm{D}$ echo or magnetic resonance imaging measurements [63]. Although studies in the pediatric population are limited, one study showed that pediatric $\mathrm{PH}$ patients have impaired $\mathrm{RV}$ function, $\mathrm{RV}$ volumes, and FAC by 3D echo [64]. 


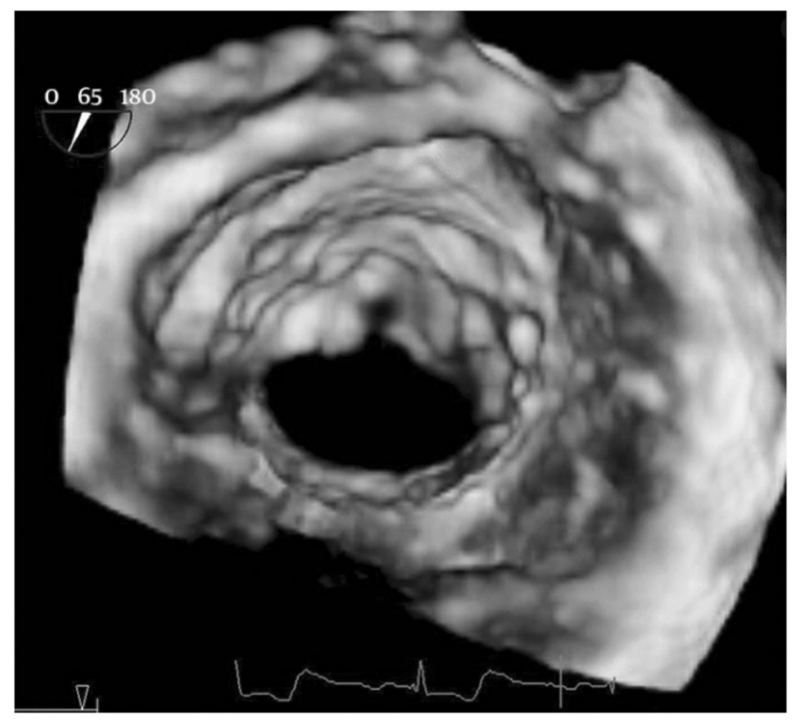

Fig. 11 3D ECHO showing the posterior mitral valve leaflet.

\section{Cardiac catheterization}

While the gold standard for the diagnosis of BPD-PH is cardiac catheterization, it is an invasive procedure and the risks and benefits must be weighed especially in the fragile neonatal population. The advantages of cardiac catheterization include direct measurement of PAP and PVR, assessment of the contribution of anatomic shunts, detection of left ventricular diastolic dysfunction, and the diagnosis of pulmonary vein stenosis [65]. This procedure in addition to being diagnostic, allows interventions to be performed. Furthermore, cardiac catheterization permits performance of vasoreactivity testing. A positive vasoreactivity test in patients with idiopathic PH can identify patients with a more favorable longterm prognosis and predict response to calcium channel blockers [66]. A recent study focusing specifically on patients with BPD-PH demonstrated that positive vasoreactivity testing during cardiac catheterization is associated with decreased mortality [10]. The need for cardiac catheterization should be weighed on a case-by-case basis but there are certain indications in which the benefit may outweigh the risk of this invasive procedure. These include assessment of patients with BPD and severe PH by echo for assessment of left ventricular diastolic dysfunction, pulmonary vein stenosis, and anatomic shunt lesions and those patients whose $\mathrm{PH}$ fails to improve with optimization of respiratory status or initiation of medical therapy [65]. In addition, assessment of vasoreactivity testing may provide useful prognostic information regarding the severity of pulmonary vascular disease and BPD [65]. While the latest guidelines suggest that every patient with idiopathic $\mathrm{PH}$ attempt to undergo cardiac catheterization and vasoreactivity testing, there are no clear guidelines for the BPD-PH population specifically [9]. The guidelines also state that in those cases where the suspicion of PH is high by noninvasive imaging and the patient is too sick to undergo cardiac catheterization, PH therapy may be initiated cautiously [9]. In these cases, catheterization remains a useful tool to serially follow PH patients who are already on medical therapy.

\section{Conclusion}

Despite improved neonatal management, BPD and BPD-PH is common in extremely premature infants and have a high incidence of morbidity and mortality. The AHA/ATS recommend screening for BPD-PH in premature infants with BPD at 36 weeks PMA, however, studies have demonstrated that irreversible changes may have occurred by that time. Noninvasive diagnosis of $\mathrm{PH}$ by echo has received increased attention recently with newer modalities and improved technology aiding in the diagnosis. However, no single noninvasive modality provides a complete assessment and diagnosis of $\mathrm{PH}$ and its associated effects on the RV. Early detection and management of BPD-PH may improve the outcomes of extremely premature infants. We suggest all premature infants with BPD should be screened prior to 36 weeks PMA for BPD-PH by functional echo. Functional echo should include LV-sEI, PAAT, TAPSE, RV FAC, strain imaging, tissue doppler, Tei index in addition to the routine echo parameters of TR jet velocity and assessment of the IVS curvature during systole.

Author contributions SD was involved in the conception and design of the work, acquisition of data, drafting and revising the manuscript and final approval of the version to be published. JCR involved in the conception and design of the work, drafting and revising the manuscript and final approval of the version to be published. AMA was involved in the conception and design of the work, acquisition of data, revising the manuscript and final approval of the version to be published. SKJ was involved in the conception and design of the work, acquisition of data, drafting and revising the manuscript and final approval of the version to be published. No funding was received for the preparation of this manuscript.

\section{Compliance with ethical standards}

Conflict of interest The authors declare no competing interests.

Publisher's note Springer Nature remains neutral with regard to jurisdictional claims in published maps and institutional affiliations.

\section{References}

1. Martin JA, Hamilton BE, Osterman MJK, Driscoll AK. Birth: final data for 2018. National Vital Statistics Report; 68. National Center for Health Statistics. 2019.

2. Northway WH Jr, Rosan RC, Porter DY. Pulmonary disease following respiratory therapy of hyaline membrane disease. Bronchopulmonary dysplasia. N Engl J Med. 1967;276:357-68. 
3. Berger RM, Beghetti M, Humpl T, Raskob GE, Ivy DD, ZhiCheng J, et al. Clinical features of paediatric pulmonary hypertension: a registry study. Lancet. 2012;379:537-46.

4. Jobe AH, Bancalari E. Bronchopulmonary dysplasia. Am J Respir Crit Care Med. 2001;163:1723-9.

5. Mourani PM, Sontag MK, Younoszai A, Miller JI, Kinsella JP, Baker CD, et al. Early pulmonary vascular disease in preterm infants at risk for bronchopulmonary dysplasia. Am J Respir Crit Care Med. 2015;191:87-95.

6. Khemani E, McElhinney DB, Rhein L, Andrade O, Lacro RV, Thomas KC, et al. Pulmonary artery hypertension in formerly preterm born infants with bronchopulmonary dysplasia: clinical features and outcomes in the surfactant era. Pediatrics. 2007;120:1260-9.

7. Abman SH, Hansmann G, Archer SL, Ivy DD, Adatia I, Chung WK, et al. Pediatric pulmonary hypertension guidelines from the American Heart Association and American Thoracic Society. Circulation. 2015;132:2037-99.

8. Galie N, Hoeper MM, Humbert M, Torbicki A, Vachiery JL, Barbera JA, et al. Guidelines for the diagnosis and treatment of pulmonary hypertension: the Task Force for the Diagnosis and Treatment of Pulmonary Hypertension of the European Society of Cardiology (ESC) and the European Respiratory Society (ERS), endorsed by the International Society of Heart and Lung Transplantation (ISHLT). Eur Heart J. 2009;30:2493-537.25.

9. Rosenzweig EB, Abman SH, Adatia I, Beghetti M, Bonnet D, Haworth S, et al. Pediatric pulmonary arterial hypertension: updates on definition, classification, diagnostics and management. Eur Respir J. 2019;53:1801916.

10. Krishnan U, Feinstein JA, Adatia I, Austin ED, Mullen MP, Hopper RK, et al. Evaluation and management of pulmonary hypertension in children with bronchopulmonary dysplasia. J Pediatr. 2017;188:24-34:e21. 34

11. Altit G, Lee HC, Hintz S, Tacy TA, Feinstein JA, Bhombal S. Practices surrounding pulmonary hypertension and bronchopulmonary dysplasia amongst neonatologists caring for premature infants. J Perinatol. 2018;38:361-7.

12. Walsh MC, Szefler S, Davis J, Allen M, Van Marter L, Abman S, et al. Summary proceedings from the bronchopulmonary dysplasia group. Pediatrics. 2006;117:S52-6.

13. Nold MF, Mangan NE, Rudloff I, Cho SX, Shariatian N, Samarasinghe TD, et al. Interleukin-1 receptor antagonist prevents murine bronchopulmonary dysplasia induced by perinatal inflammation and hyperoxia. Proc Natl Acad Sci. 2013;110:14384-9.

14. Qasim A, Dasgupta S, Aly AM, Jain SK. Sildenafil use in the treatment of bronchopulmonary dysplasi-associated pulmonary hypertension: a case series. AJP Rep. 2018;8:e219-22.

15. Allen HD, Shaddy RE, Penny DJ, Feltes DF, Cetta F. Heart disease in infants, children and adolescents. Vol. 1, Chapter 12 304-7.

16. Ashley EA, Niebauer J. Understanding the echocardiogram. Cardiology explained. London: Remedica, 2004

17. Berkelhamer SK, Mestan KK, Steinhorn RH. Pulmonary hypertension in bronchopulmonary dysplasia. Semin Perinatol. 2013;37:124-31.

18. Walsh MC, Wilson-Costello D, Zadell A, Newman N. Fanaroff A. Safety, reliability, and validity of a physiologic definition of bronchopulmonary dysplasia. J Perinatol. 2003;23:451-6.

19. Hansmann G, Sallmon H, Roehr CC, Kourembanas S, Austin ED, Koestenberger M. Pulmonary hypertension in bronchopulmonary dysplasia. Pediatr Res. 2020. https://doi.org/10.1038/s41390-0200993-4

20. Mourani PM, Sontag MK, Younoszai A, Ivy DD, Abman SH. Clinical utility of echocardiography for the diagnosis and management of pulmonary vascular disease in young children with chronic lung disease. Pediatrics. 2008;121:317-25.
21. Kumar V, Hutchison A, Lakshminrusimha S, Morin F, Wynn R, Ryan R. Characteristics of pulmonary hypertension in preterm neonates. J Perinatol. 2007;27:214-9.

22. King M, Braun H, Goldblatt A, Liberthson R, Weyman A. Interventricular septal configuration as a predictor of right ventricular systolic hypertension in children: a cross sectional echocardiographic study. Circulation. 1983;68:68-75.

23. Parasuraman S, Walker S, Loudon BL, Gollop ND, Wilson AM, Lowery C. Assessment of pulmonary artery pressure by echocardiography- A comprehensive review. Int J Cardiol Heart Vasc. 2016 Sep;12:45-51.

24. Fisher MR, Forfia PR, Chamera E, Housten-Harris T, Champion HC, Girgis RE, et al. Accuracy of Doppler echocardiography in the hemodynamic assessment of pulmonary hypertension. Am J Respir Crit Care Med. 2009;179:615-21.

25. Kostenberger M. Transthoracic echocardiography in the evaluation of pediatric pulmonary hypertension and ventricular dysfunction. Pulm Circ. 2016;6:15-29.

26. Masuyama T, Kodama K, Kitabatake A, Sato H, Nanto S, Inoue M. Continuous-wave Doppler echocardiographic detection of pulmonary regurgitation and its application to noninvasive estimation of pulmonary artery pressure. Circulation. 1986;74:484-92.

27. Revanna GK, Kunjunju A, Sehgal A. Bronchopulmonary dysplasia associated pulmonary hypertension: making the best use of bedside echocardiography. Prog Pediatr Cardiol. 2017;46:39-43.

28. Ehrmann DE, Mourani PM, Abman SH, Poindexter BB, Morrow LA, Wagner BD, et al. Echocardiographic measurements of right ventricular mechanics in infants with bronchopulmonary dysplasia at 36 weeks post-menstrual age. J Pediatr. 2018;203:210-7.

29. Levy PT, Patel MD, Groh G, Choudhry S, Murphy J, Holland MR, et al. Pulmonary artery acceleration time provides a reliable estimate of invasive pulmonary hemodynamics in children. J Am Soc Echocardiogr. 2016;29:1056-65.

30. Cevik A, Kula S, Olgunturk R, Tunaoglu FS, Oguz AD, Saylan B, et al. Assessment of pulmonary arterial hypertension and vascular resistance by measurements of the pulmonary arterial flow velocity curve in the absence of a measurable tricuspid regurgitant velocity in childhood congenital heart disease. Pediatr Cardiol. 2013;34:646-55.

31. Granstam SO, Björklund E, Wikström G, Roos MW. Use of echocardiographic pulmonary acceleration time and estimated vascular resistance for the evaluation of possible pulmonary hypertension. Cardiovasc Ultrasound. 2013;11:7.

32. Arkles JS, Opotowsky AR, Ojeda J, Rogers F, Liu T, Prassana V, et al. Shape of the right ventricular Doppler envelope predicts hemodynamics and right heart function in pulmonary hypertension. Am J Respir Crit Care Med. 2011;183:268-76.

33. Kosturakis D, Goldberg SJ, Allen HD, Loeber C. Doppler echocardiographic prediction of pulmonary arterial hypertension in congenital heart disease. Am J Cardiol. 1984;53:1110-5.

34. Matsuda M, Sekiguchi T, Sugishita Y, Kuwako K, Iida K, Ito I. Reliability of non-invasive estimates of pulmonary hypertension by pulsed Doppler echocardiography. Br Heart J. 1986;56:158-64.

35. Miller D, Farah MG, Liner A, Fox K, Schluchter M, Hoit BD. The relation between quantitative right ventricular ejection fraction and indices of tricuspid annular motion and myocardial performance. J Am Soc Echocardiogr. 2004;17:443-7.

36. Koestenberger M, Nagel B, Ravekes W, Everett AD, Stueger H, Heinzl B, et al. Systolic right ventricular function in pediatric and adolescent patients with tetralogy of Fallot: echocardiography versus magnetic resonance imaging. J Am Soc Echocardiogr. 2011;24:45-52.

37. Jone PN, Ivy DD. Echocardiography in pediatric pulmonary hypertension. Front Pediatr. 2014;2:124.

38. Lamia B, Teboul JL, Monnet X, Richard C, Chemla D. Relationship between the tricuspid annular plane systolic excursion 
and right and left ventricular function in critically ill patients. Intensive Care Med. 2007;33:2143-9.

39. Koestenberger M, Ravekes W, Everett A, Stueger HP, Heinzl B, Gamillscheg A, et al. Right ventricular function in infants, children and adolescents: reference values of the tricuspid annular plane systolic excursion (TAPSE) in 640 healthy patients and calculation of $\mathrm{z}$ score values. $\mathrm{J}$ Am Soc Echocardiogr. 2009;22:715-9.

40. Nunez-Gill IJ, Rubio MD, Carton AJ, Lopez-Romero P, Deiros L, Garcia-Guereta L. Determination of normalized values of the Tricuspid Annular Plane Systolic Excursion (TAPSE) in 405 Spanish children and adolescents. Rev Espanola De Cardiol. 2011;64:674-80.

41. Forfia P, Fisher M, Mathai S, Housten-Harris T, Hemnes A, Borlaug B, et al. Tricuspid annular displacement predicts survival in pulmonary hypertension. Am J Respir Crit Care Med. 2006;174:1034-41.

42. Koestenberger M, Nagel B, Avian A, Ravekes W, Sorantin E, Cvirn G, et al. Systolic right ventricular function in children and young adults with pulmonary artery hypertension secondary to congenital heart disease and tetralogy of Fallot: tricuspid annular plane systolic excursion (TAPSE) and magnetic resonance imaging data. Congenit Heart Dis. 2012;7:250-8.

43. Ploegstra MJ, Douwes JM, Roofthooft MT, Zijlstra WM, Hillege HL, Berger RM. Identification of treatment goals in paediatric pulmonary arterial hypertension. Eur Respir J. 2014;44:1616-26.

44. Bano M, Kanaan UB, Ehrlich AC, McCracken C, Morrow G, Oster ME, et al. Improvement in tricuspid annular plane systolic excursion with pulmonary hypertension therapy in pediatric patients. Echocardiography. 2015;32:1228-32.

45. Di Maria MV, Younoszai AK, Mertens L, Landeck BF II, Ivy DD, Hunter K, et al. RV stroke work in children with pulmonary arterial hypertension: estimation based on invasive haemodynamic assessment and correlation with outcomes. Heart. 2014;100:1342-7.

46. Levy PT, Dioneda B, Holland MR, Sekarski TJ, Lee CK, Mathur A, et al. Right ventricular function in preterm and term neonates: reference values for right ventricle areas and fractional area of change. J Am Soc Echocardiogr. 2015;28:559-69.

47. Shah AM, Solomon SD. Myocardial deformation imaging. Circulation. 2012;125:244-8.

48. Li Y, Xie M, Wang X, Lu Q, Fu M. Right ventricular regional and global systolic function is diminished in patients with pulmonary arterial hypertension: a 2-dimensional ultrasound speckle tracking echocardiography study. Int J Cardiovasc Imaging. 2013;29:545-51.

49. Filusch A, Mereles D, Gruenig E, Buss S, Katus HA, Meyer FJ, et al. Strain and strain rate echocardiography for evaluation of right ventricular dysfunction in patients with idiopathic pulmonary arterial hypertension. Clin Res Cardiol. 2010;99:491-8.

50. Okumura K, Humpl T, Dragulescu A, Mertens L, Friedberg MK. Longitudinal assessment of right ventricular myocardial strain in relation to transplant-free survival in children with idiopathic pulmonary hypertension. J Am Soc Echocardiogr. 2014;27:1344-51.

51. Altit G, Bhombal S, Feinstein J, Hopper RK, Tacy TA. Diminished right ventricular function at diagnosis of pulmonary hypertension is associated with mortality in bronchopulmonary dysplasia. Pul Circ. 2019;9:2045894019878598.

52. Eidem BW, McMahon CJ, Cohen RR, Wu J, Finkelshteyn I, Kovalchin JP, et al. Impact of cardiac growth on Doppler tissue imaging velocities: a study in healthy children. J Am Soc Echocardiogr. 2004;17:212-21.

53. Hammerstingl C, Schueler R, Bors L, Momcilovic D, Pabst S, Nickenig G. Diagnostic value of echocardiography in the diagnosis of pulmonary hypertension. PLoS One. 2012;7:e38519.

54. Lammers AE, Haworth SG, Riley G, Maslin K, Diller GP, Marek J. Value of tissue Doppler echocardiography in children with pulmonary hypertension. J Am Soc Echocardiogr. 2012;25:504-10.

55. Takatsuki S, Nakayama T, Jone PN. Tissue doppler imaging predicts adverse outcome in children with idiopathic pulmonary arterial hypertension. J Pediatr. 2012;161:1126-31.

56. Tei C, Ling LH, Hodge DO, Bailey KR, Oh J, Rodeheffer RJ, et al. New index of combined systolic and diastolic myocardial performance: a simple and reproducible measure of cardiac function: a study in normals and dilated cardiomyopathy. J Cardiol. 1995;26:357-66.

57. Vonk MC, Sander MH, van den Hoogen FH, van Riel PL, Verheugt FW, van Dijk AP. Right ventricle Tei-index: a tool to increase the accuracy of non-invasive detection of pulmonary arterial hypertension in connective tissue diseases. Eur $\mathrm{J}$ Echocardiogr. 2007;8:317-21.

58. Vorhies EE, Gajarski RJ, Yu S, Donohue JE, Fifer CG. Echocardiographic evaluation of ventricular function in children with pulmonary hypertension. Pediatr Cardiol. 2014;35:759-66.

59. Seo YH, Choi HJ. Clinical utility of echocardiography for early and late pulmonary hypertension in preterm infants: relation with Bronchopulmonary Dysplasia. J Cardiovasc Ultrasound. 2017;25:124-30.

60. Crowe T, Jayasekera G, Peacock AJ. Non-invasive imaging of global and regional cardiac function in pulmonary hypertension. Pulm Circ. 2018;8:1-20.

61. Knight DS, Grasso AE, Quail MA, Muthurangu V, Taylor AM, Toumpanakis AM, et al. Accuracy and reproducibility of right ventricular quantification in patients with pressure and volume overload using single-beat three- dimensional echocardiography. J Am Soc Echocardiogr. 2015;28:363-74.

62. Kong D, Shu X, Dong L, Pan C, Cheng L, Yao H, et al. Right ventricular regional systolic function and dyssynchrony in patients with pulmonary hypertension evaluated by three-dimensional echocardiography. J Am Soc Echocardiogr. 2013;26:649-56.

63. Grapsa J, O'Regan DP, Pavlopoulos H, Durighel G, Dawson D, Nihoyannopoulos P. Right ventricular remodelling in pulmonary arterial hypertension with three-dimensional echocardiography: comparison with cardiac magnetic resonance imaging. Eur $\mathbf{J}$ Echocardiogr. 2010;11:64-73.

64. Jone PN, Pan Z, Schafer M, Bremen C. 3D echocardiographic evaluation of right ventricular function and strain: a prognostic study in paediatric pulmonary hypertension. Eur Heart J Cardiovasc Imaging. 2018;19:1026-33.

65. Frank BS, Schafer M, Grenolds A, Ivy DD, Abman SH, Darst JR. Acute vasoreactivity testing during cardiac catheterization of neonates with bronchopulmonary dysplasia-associated pulmonary hypertension. J Pediatr. 2019;208:127-33.

66. Del Cerro MJ, Moledina S, Haworth SG, Ivy D, Al Dabbagh M, Banjar $\mathrm{H}$, et al. Cardiac catheterization in children with pulmonary hypertensive vascular disease: consensus statement from the Pulmonary Vascular Research Institute, Pediatric and Congenital Heart Disease Task Forces. Pulm Circ. 2016;6:118-25. 